$\mathbf{R}_{\text {ESearch }} \mathbf{P}_{\text {APER }} \longrightarrow$ FOOD SCIENCE. e ISSN-2230-9403 - Visit us :
www.researchjournal.co.in
Volume $9 \mid$ Issue $1 \mid$ April, 2018 | 134-137
DOI : 10.15740/HAS/FSRJ/9.1/134-137

\title{
Nutritional assessment of agriculture adult women (18-40 years) in Sultanpur district
}

\author{
Mamta Jaiswal and Priyanka Chaurasiya
}

\begin{abstract}
The impact of agriculture interventions on nutritional status in participating households, and to analyze the characteristics of interventions that improved nutrition outcomes. We identified and reviewed reports describing 30 agriculture interventions that measured impact on nutritional status. The interventions reviewed included home gardening, livestock, mixed garden and livestock, cash cropping, and irrigation. We examined the reports for the scientific quality of the research design and treatment of the data. We also assessed whether the projects invested in five types of 'capital' (physical, natural, financial, human and social) as defined in the Sustainable Livelihoods Framework, a conceptual map of major factors that affect people's livelihoods. Most agriculture interventions increased food production, but did not necessarily improve nutrition or health within participating households. Nutrition was improved in 11 of 13 home gardening interventions, and in 11 of 17 other types of intervention. Of the 19 interventions that had a positive effect on nutrition, 14 of them invested in 4 or 5 types of capital in addition to the agriculture intervention. Of the nine interventions that had a negative or no effect on nutrition, only one invested in four or five types of capital. Those agriculture interventions that invested broadly in different types of capital were more likely to improve nutrition outcomes. Those projects which invested in human capital (especially nutrition education and consideration of gender issues), and other types of capital, had a greater likelihood of effecting positive nutritional change, but such investment is neither sufficient nor always necessary to effect change. Although poor dietary intake is a common cause of micronutrient deficiencies, the root causes is linked with low socio-economic status and lack of knowledge about healthy eating patterns. This study was performed to determine the impact of nutritional assessment of agriculture adult women in sultanpur district (18-40) year for the research survey method was used for the collection 100 data. Result show that maximum women's were positive impact of nutrition education positive nutritional assessment of agriculture women.
\end{abstract}

Key Words : Interventions, Assessment, Micronutrient, Gardening, Consideration

How to cite this article : Jaiswal, Mamta and Chaurasiya, Priyanka (2018). Nutritional assessment of agriculture adult women (1840 years) in Sultanpur district. Food Sci. Res. J., 9(1): 134-137, DOI : 10.15740/HAS/FSRJ/9.1/134-137. 